\title{
PRÉFACE
}

\section{à la seconde édition}

En préparant cette édition, j'ai voulu autant que possible tenir compte des objections qui ont été formulées contre les idées que je défends dans mes $\dot{E} t u d e s$ sur la nature humaine.

C'est le clinicien bien connu de Montpellier. M. le $D^{r}$ Grasset, qui en a fait la critique la plus développée dans son article " la fin de la vie " (Revue de philosophie, $1^{\text {er }}$ août 1903). M. Grasset pense que, dans mon système, il n'y a " aucune place pour l'altruisme" et que "la recherche de la longévité et de la mort naturelle ne peut pas constituer le fondement de la morale, parce que dans cet élément, comme dans tous les éléments tirés de la biologie, il n'y a aucune place pour l'obligation". Il est cependant évident que, pour arriver au but de la vie individuelle, il faut le concours de la société et par conséquent un échange de services entre individus. La conviction que, sans ce concours, l'individu ne pourra jamais atteindre sa fin normale, constitue, je pense, une obligation de répondre aux services d'autrui par des services réciproques, beaucoup plus efficace que tous les commandements religieux. C'est tout à fait comme 
dans le domaine de la préservation contre les maladies. Si quelqu un acquiert la certitude que, pour ne pas risquer de mourir prématurément de la peste, il faut détruire les rats, ces véhicules du virus pesteux, il se considérera certainement comme beaucoup plus obligé de détruire ces rongeurs que de se flageller ou d'exercer n'importe quel autre rite religieux. La conviction que les mesures contre les maladies ne sont efficaces que quand elles sont prises en commun et non par des individus isolés constituera une obligation beaucoup plus importante que n'importe quel commandement religieux. Le sentiment altruiste qui est bien capable de se développer chez des gens pénétrés de connaissances exactes, ne fera qu'aider à l'action commune pour assurer l'accomplissement du cycle complet et normal de la vie.

M. Grasset pense aussi qu'il " est impossible de modifier assez notre vie et notre organisme pour arriver à la mort naturelle ". Je suis d'un avis diamétralement opposé en cette matière et je ne vois pas pourquoi la science, qui a déjà réalisé tant de progrès, ne serait pas capable d'arriver à un résultat semblable à celui qui a pu être atteint dans les temps bibliques?

Un autre de mes critiques, persuadé qu'il n'y a que la religion qui soit capable de guider les hommes, me reproche de recourir aux hypothèses et de ne pas avoir " démontré qu'on puisse arriver à corriger, en supposant qu'elles existent, les désharmonies de notre nature " ( $\mathrm{D}^{\mathrm{r}}$ L. M., dans Cosmos, 25 avril 1903, p. 523). Je n'ai jamais caché à mes lecteurs que 
je n'ai cberché qu’à présenter un système logique, basé sur des hypothèses. Aussi je l'ai donné comme un programme, capable d'être utilisé par des cher. cheurs, pénétrés de la méthode scientifique. Mais mon contradicteur ne fournit de son coté non plus aucune preuve de ce que les suppositions que je considère comme réalisables ne le seront jamais.

Le physiologiste bien connu, M. Dastre, dans une revue, pleine de bienveillance pour mon œuvre, se demande si la perspective de l'acquisition de linstinct de la mort naturelle sera suffisante pour apaiser la peur de la mort chez les jeunes gens et chez les hommes mùrs Revue des Deux-Mondes, $1^{\text {er }}$ avril 1903, p. 708). Je ne vois pas pourquoi cette espérance ne suffirait pas à tranquilliser l'àme angoissèe. M. Dastre se demande aussi si la disparition, quoique naturelle, ne déchirera pas le cœur des proches? Même à présent, la mort des parents ayant vécu de longues années, trouble moins que leur disparition prématurée. On acceptera encore mieux la mort des proches, survenue au moment de l'acquisition de l'instinct de la mort naturelle et de la " satiété des jours, " comme dans les temps bibliques.

Je n'ai aucune prétention de résnudre tous les problèmes relatifs au but de la vie humaine et à la base de la morale rationnelle. mais il me semble que mon système est capable d'éclaircir ces questions jusqu'à un certain point et d'indiquer la voie dans laquelle elles peuvent être étudiées.

Je dois signaler que ces Etudes ne représentent nullement une " suite de piquantes causeries", 
comme elles ont été qualifiées dans une revue. Elles sont plutót la synthèse de toute une vie consacrée à la science. 11 y a plus de trente ans que je professe dans mes écrits cette théorie des désharmonies de la nature humaine qui a servi de base à mes idées sur la Philosophie et la Morale. Plus tard, avec une expérience plus grande de la vie, j'ai appris la différence des sensations et des sentiments aux diverses périodes de l'existence humaine. Tout l'ensemble de ces données s'est cristallisé sous la forme que je leur ai donnée dans ce livre.

Toutes les critiques n'ayant amené que très peu de changements dans mes idées, il en résulte que cette seconde édition ne diffère que fort peu de la première. Aussi j'engage les personnes qui sont en possession de mon livre à ne pas se procurer cette seconde édition.

Parmi les quelques modifications que j'ai été amené à accepter, je mentionne le passage sur la décadence de l'art au moyen áge. M. C. Saint-Saěns a attiré mon attention sur l'inexactitude de l'opinion de Taine qui m'avait servi de guide. Il m'a recommandé l'ouvrage de Viollet-le-Duc, comme beaucoup plus exactement documenté J'ai profité du conseil de l'illustre compositeur el je l'en remercie.

Eule Metchnikofr.

Paris, 27 octobre 1903. 